\title{
Exploratory Factor Analysis: Conceptualization, Reliability and Validity of Job Performance
}

\author{
Rohana Mat Som, Raja Munirah Raja Mustapha, Abdul Kadir Othman, Rozilah Abdul Aziz, and \\ Shereen Noranee
}

\begin{abstract}
The study attempts to examine the psychometric properties of the job performance constructs by integrating the two subscales; task performance and contextual performance. Results from preliminary psychometric conclude that the nursing performance scale has good internal consistency and good criterion validity. A measure developed by Greenslade and Jimmieson was used as a reliable and valid tool in assessing nurses' job performance. The results of exploratory factor analysis confirmed that the measurement scale used in this study satisfactorily met the standards of validity and reliability analyses. Exploratory factor analysis confirmed five dimensions of task performance namely: technical care, non-job specific behavior, provision of information, provision of support and coordination of care. Meanwhile, three dimensions of Contextual Performance namely: job-task support, interpersonal support and organizational support; as the dimensions that measure Job Performance constructs.
\end{abstract}

Index Terms-Job performance, task performance, contextual performance.

\section{INTRODUCTION}

Job performance contributes to improve several aspects in employees such as behavior, attitudes and traits which help to increase the productivity of an organization. Employees' behavior can be transformed into performance from just a thought to action [1] Therefore, a complete view of performance can be achieved if the definition of job performance taken into account both behavior and outcomes. [2] defines job performance as "a kind of individual behavior for fulfilling the expectations, regulations of an organization and needs of his or her formal role when he or she is a member of the organization."

In general, some jobs require the job incumbent to make judgments on certain situations and give practical response accordingly. The effectiveness of the response made will then affect job performance. In addition, [3] categorize individual performance into two categories: task performance and contextual performance. Task performance includes behaviors that contribute to the core transformation and maintenance activities in an organization including delivering services and managing subordinates [4] Contextual performance refers to behaviors that contribute to the culture and climate of the organization in the context of transformation and maintenance activities carried out such as helping subordinates, adhering to rules and procedures and providing full support towards the organization [4].

Manuscript received January 10, 2014; revised March 12, 2014.

The authors are with the Universiti Teknologi Mara, Malaysia (e-mail: rohanamsom@gmail.com).

\section{Job Performance IN NURSING}

Performance of nurses is regarded as an important part in the provision of quality care in the hospital setting. According to [5] patient safety is a serious issue that causes the increase in adverse events such as medication errors, pressure ulcers, and postoperative complications [6] adverse drug events, patient falls and injuries, nosocomial infections, and skin breakdown [7].

Consequently, workload is said to be one of the causes of adverse events. Quality and safety of care may affect due to nurses' workload which eventually impact job performance This is supported by [8] who claimed that high nursing workload poorly affect quality and safety of care. Additionally, due to an increase number of patients, many hospitals are facing with understaffing problem [8]. They suggest once performance obstacles are identified, the work system is to be redesigned in order to eliminate further consequences that can affect the effectiveness of the overall organization.

Failure in providing quality service to customers is the result of performance-based issues faced by the public service due to poor job performance [9]. Several factors contribute to the poor performance among government servants. Some of the factors highlighted in the literature are inappropriate performance indicators [10]-[13] challenges in fulfilling stakeholders' needs [14], employees' personal traits and behavior [15] top management failure in identifying performance gap [16]-[18] unclear organizational goals [17], [19] and unfair reward allocation [20], [22].

There are various scales introduced to gauge nursing's performance. The scales were dated as early as 1960s and 1970s. Of the various approaches in measuring competence, two commonly used scales are [23] and the Slater Nursing Competencies Rating scale [24]. Since then there is an expansion of the nursing roles taken place within the healthcare system in which it requires an updated measure. Furthermore, those scales mentioned earlier have certain limitations that may influence the final results. Therefore, since a larger sample of nurses from different regions are used, a measure developed by [25] has been chosen as a reliable and valid tool in assessing nurses' job performance. Another reason for choosing the measure is that no other measures, measure nurses' job performance separately for task performance and contextual performance [25].

\section{TASK PERFORMANCE}

The behaviors comprise of task performance in nursing 
are categorized as technical care, non-job specific behavior, provision of information, provision of support and coordination of care.

In order to assist the patients' speedy recovery, nurses may prepare a plan of care after consulting the family and the physician [25]. This helps nurses to evaluate the patient's progress as well as the care plan for its suitability on the patient. Technical care also may include assisting patients with daily activities, treatment and medication.

Next, non-job specific behavior. It incorporates those common tasks done by nurses but not stipulated in the scope of nursing practice. Among tasks identified fall into this category are administrative duties such as preparing reports for patient progress, rearranging medical cards; recognizing and meeting the allied health needs of patients such as accompanying patients while waiting for their family members upon discharge from hospital [25].

Third, provision of information that provides patients and their family members with the information and steps to follow when following any treatments is among the job a nurse. Informational support include educating the patient about his progress [25], as far as medication is concerned, what kind of progress will be experienced by the patient and what will they encounter during the process.

Fourth, provision of support which involves providing emotional support to patients and their family members about any concerns and [25] as well as providing necessary comfort to ease the situation.

Lastly, coordination of care in which nurses updating the patients' progress from time-to-time among nursing team [25]), so that everyone aware and ready for an immediate action to take, if needed. In addition, this ensures all team members take note of the patient's history in order to record the progress of patients' condition with the given treatment. It is noted that nurses who are satisfied with the interaction among nurse-nurse; nurse-physician seem to be committed to the organization. Positive interaction and team spirit increase the affection among employees and enhance the sense of belong to the organization.

\section{Contextual Performance}

To date, there are limited studies on contextual performance have been carried out on government servants [26] despite strong recommendation by scholars on the need to study job behaviors among government servants [27] The roles of government servants as the backbone of the public sectors cannot be denied in which they are hoped to provide excellent service from time to time. It is believed that contextual performance as constructive behaviors since they are found to assist employees in completing their task performance for the sake of organizational effectiveness [28]

The first dimension of contextual performance is job-task support. At times nurses have to stay late to aid patients and/or their family members to make certain arrangements pertaining to their stay or discharge from the hospital.

The second dimension of contextual performance is Interpersonal Support. Research addressing the effectiveness of teamwork and collaboration among teams has been conducted to promote healthy work environment in healthcare setting. Descriptive studies on the characteristics of a team that influence patient, nurse and organizational outcomes have been carried such as nurse-physician collaboration, social support, conflict, communication and relationship dimensions, and personal and social support [29]. Reports of collaboration of nurses-physicians; attending physicians and resident physicians, and patient outcomes on patients transferred from the ICU into wards reveal evidence that nurse-reported collaboration was positively associated with patient outcomes. Likewise, reports on collaboration between nurses-resident/attending physicians' show negatively associated with patient outcomes. These results suggest that the differences in collaboration between both nurses and physicians influence decision-making. In addition [29] stated that the differences have impact on developing support by physicians in implementing interventions to increase collaboration between both professions [30].

In addition, teamwork has positive attributes towards psychological health and wellbeing of the employees. It is reported that such collaboration has lowered stress level and improve effectiveness and innovation among nurses [31].

The final dimension is known as Organizational support. The role of supportive management practices and perceived costs of seeking support on the performance of primary nurses results in enhanced performance that show positive correlation between supervisor support and nurses' performance [32]. It is evident that organizational support is responsible to improve the performance of primary nurses. In their study, [33] found that the job satisfaction differs in how individuals value their organizations in term of their readiness to invest their "full selves" when carrying out their responsibilities toward the organizations.

Nurses who perceive that their organization values and supports their contributions and well-being by providing assistance in doing their job effectively will be in less stress and more committed [34]. They will be more loyal to the organization as compared to those who feel that the organization does not appreciate what they have done. This is consistent with a study by [35] that showed high commitment among nurses whose organizations value their contributions and care for their well-being.

\section{Methodology}

\section{A. Procedures}

A total of 150 questionnaires were distributed to nurses at government hospitals with a return rate of 80 percent or 120 respondents. However, 22 cases were eliminated due to missing data and outliers. a total of 98 respondents were used for factor analysis purposes.

\section{B. Instruments}

The study, utilized the questionnaire developed by Greenslade and Jimmieson [36] to measure nurses' job performance in which 63-items assesses the taxonomy of integrated behaviors of nurses that reflect task performance and contextual performance. Out of 63-items, 36-items will ask questions pertaining to task performance behaviors in which nurses are required to rate how well their unit or ward functions in several activities. The ratings will be based on 7-point Likert scales, ranging from much below average (1) 
to much above average (7). Examples of items such as: "explaining to patients what to expect when they leave the hospital," and "Administering medications and treatments." The coefficient for the items is 0.94 (Greenslade \& Jimmieson [36]). Meanwhile 27-items examining contextual performance behaviors and require nurses to identify and rate how frequent the listed activities in their ward are completed. The same 7-point Likert scales will be used, ranging from not at all (1) to a great deal (7). Examples of items such as: "Consulting amongst each other each other when actions might affect other nurses in the unit," and "Complying with hospital rules, regulations and procedures, even when no one is watching." The coefficient for the items is 0.91 (Greenslade \& Jimmieson, [36]).

\section{RESULTS}

The EFA results are shown in Table II. Based on the sample of 98 respondents, the 41 items loaded onto eight

TABLE I: PSYCHOMETRIC PROPERTIES OF THE EIGHT DIMENSIONS OF JOB PERFORMANCE INVENTORY

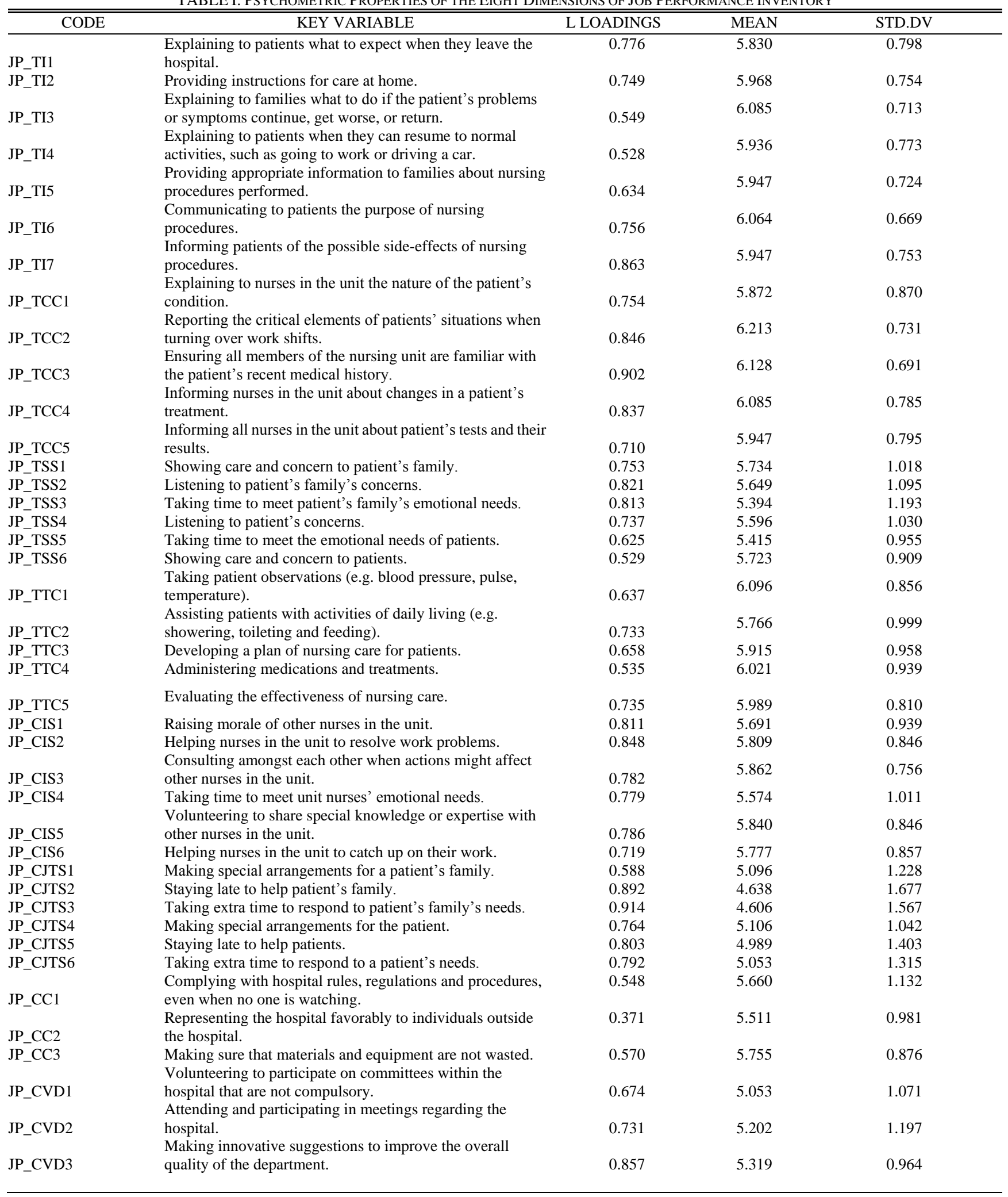


factors with the factor loadings are greater than 0.600 . Pallant reported that KMO value should be 0.6 above and the Barletts' Test of Sphericity valued should be significant $(0.5$ or smaller). Kaiser's normalization for this data set was .801 , and the Bartletts' test is significant $(p=0.000)$ which indicates a satisfactory sample factor analysis is appropriate. An eigenvalue of 1.0 was set as the minimum criterion for identifying a factor and used as a cutoff value for extraction.

The results of the analysis indicated the present of only the expected eight factors (a scree plot confirmed this number of factors) shows the items loaded on each construct. The eight factors explained 79.84 percent of the variance, the factor loadings were all greater than 0.600 and the cross loadings were minimal.

TABLE II: RELIABILITY OF SCALE

\begin{tabular}{|c|c|c|c|}
\hline $\mathrm{CODE}$ & KEY VARIABLE & MSA & $\begin{array}{l}\text { CRONBACH } \\
\text { ALPHA }\end{array}$ \\
\hline JP_TI1 & Explaining to patients what to expect when they leave the hospital. & 0.833 & 0.899 \\
\hline JP_TI2 & $\begin{array}{l}\text { Providing instructions for care at home. } \\
\text { Explaining to families what to do if the patient's problems or symptoms }\end{array}$ & & \\
\hline JP_TI3 & $\begin{array}{l}\text { continue, get worse, or return. } \\
\text { Explaining to patients when they can resume to normal activities, such as going }\end{array}$ & & \\
\hline JP_TI4 & to work or driving a car. & & \\
\hline JP_TI5 & $\begin{array}{l}\text { Providing appropriate information to families about nursing procedures } \\
\text { performed. }\end{array}$ & & \\
\hline JP_TI6 & Communicating to patients the purpose of nursing procedures. & & \\
\hline JP_TI7 & Informing patients of the possible side-effects of nursing procedures. & & \\
\hline JP_TCC1 & Explaining to nurses in the unit the nature of the patient's condition. & 0.838 & 0.878 \\
\hline JP_TCC2 & $\begin{array}{l}\text { Reporting the critical elements of patients' situations when turning over work } \\
\text { shifts. }\end{array}$ & & \\
\hline JP_TCC3 & $\begin{array}{l}\text { Ensuring all members of the nursing unit are familiar with the patient's recent } \\
\text { medical history. }\end{array}$ & & \\
\hline JP_TCC4 & Informing nurses in the unit about changes in a patient's treatment. & & \\
\hline JP_TCC5 & Informing all nurses in the unit about patient's tests and their results. & & \\
\hline JP_TSS1 & Showing care and concern to patient's family. & 0.836 & 0.916 \\
\hline JP_TSS2 & Listening to patient's family's concerns. & & \\
\hline JP_TSS3 & Taking time to meet patient's family's emotional needs. & & \\
\hline JP_TSS4 & Listening to patient's concerns. & & \\
\hline JP_TSS5 & Taking time to meet the emotional needs of patients. & & \\
\hline JP_TSS6 & Showing care and concern to patients. & & \\
\hline JP_TTC1 & Taking patient observations (e.g. blood pressure, pulse, temperature). & 0.740 & 0.890 \\
\hline $\begin{array}{l}\text { JP_TTC2 } \\
\text { JP_TTC3 }\end{array}$ & $\begin{array}{l}\text { Assisting patients with activities of daily living (e.g. showering, toileting and } \\
\text { feeding). } \\
\text { Developing a plan of nursing care for patients. }\end{array}$ & & \\
\hline JP_TTC4 & Administering medications and treatments. & & \\
\hline JP_TTC5 & Evaluating the effectiveness of nursing care. & & \\
\hline JP_CIS1 & Raising morale of other nurses in the unit. & 0.848 & 0.936 \\
\hline JP_CIS2 & Helping nurses in the unit to resolve work problems. & & \\
\hline JP_CIS3 & $\begin{array}{l}\text { Consulting amongst each other when actions might affect other nurses in the } \\
\text { unit. }\end{array}$ & & \\
\hline JP_CIS4 & Taking time to meet unit nurses' emotional needs. & & \\
\hline JP_CIS5 & $\begin{array}{l}\text { Volunteering to share special knowledge or expertise with other nurses in the } \\
\text { unit. }\end{array}$ & & \\
\hline JP_CIS6 & Helping nurses in the unit to catch up on their work. & & \\
\hline JP_CJTS1 & Making special arrangements for a patient's family. & 0.785 & 0.938 \\
\hline JP_CJTS2 & Staying late to help patient's family. & & \\
\hline JP_CJTS3 & Taking extra time to respond to patient's family's needs. & & \\
\hline JP_CJTS4 & Making special arrangements for the patient. & & \\
\hline JP_CJTS5 & Staying late to help patients. & & \\
\hline JP_CJTS6 & Taking extra time to respond to a patient's needs. & & \\
\hline JP_CC1 & $\begin{array}{l}\text { Complying with hospital rules, regulations and procedures, even when no one } \\
\text { is watching. }\end{array}$ & 0.655 & 0.652 \\
\hline JP_CC2 & Representing the hospital favorably to individuals outside the hospital. & & \\
\hline JP_CC3 & Making sure that materials and equipment are not wasted. & & \\
\hline JP_CVD1 & $\begin{array}{l}\text { Volunteering to participate on committees within the hospital that are not } \\
\text { compulsory. }\end{array}$ & 0.699 & 0.831 \\
\hline JP_CVD2 & Attending and participating in meetings regarding the hospital. & & \\
\hline JP_CVD3 & $\begin{array}{l}\text { Making innovative suggestions to improve the overall quality of the } \\
\text { department. }\end{array}$ & & \\
\hline
\end{tabular}




\section{CONCLUSION}

The result of the findings proved the construct validity of nurses' job performance. In addition, the instrument used in this study can be used to measure job performance of nurses in Malaysia. This study has given a significant contribution in terms of construct development of a more comprehensive job performance measure. Based on the psychometric properties of the instrument, it is found that both constructs are equal and exceed the measurement levels. The instrument is therefore, may be used by researchers to measure nurses' job performance since all the items measure the construct accordingly.

\section{REFERENCES}

[1] L. Kalyani, "An empirical investigation of the impact of organizational factors on the perceived job performance of shop floor employees of large scale garment industries in Sri Lanka," Sabaragamuwa University Journal, vol. 6, no. 1, pp. 82-92, 2006.

[2] J. P. Campbell, J. J. McHenry, and L. L. Wise, "Modeling job performance in a population of jobs," Personnel Psychology, vol. 43, no. 2, pp. 313-575, 1990.

[3] S. J. Motowidlo and J. R. V. Scotter, "Evidence that task performance should be distinguished from contextual performance," Journal of Applied Psychology, vol. 79, no. 4, pp. 475, 1994.

[4] S. Motowidlo and M. Schmit, "Performance assessment in unique jobs," The Changing Nature of Job Performance: Implications for Staffing, Motivation, and Development, Pulakos (Eds.), 1999, pp. 56-86.

[5] M. A. Ma and W. Ob, Nursing Practice Environment and Patient Outcomes in University Hospitals in Malaysia.

[6] S.-H. Cho et al., "The effects of nurse staffing on adverse events, morbidity, mortality, and medical costs," Nursing Research, vol. 52, no. 2, pp. 71-79, 2003.

[7] P. I. Buerhaus and J. Needleman, "Policy implications of research on nurse staffing and quality of patient care," Policy, Politics, and Nursing Practice, vol. 1, no. 1, pp. 5-15, 2000.

[8] A. Gurses, P. Carayon, and M. Wall, "Impact of performance obstacles on intensive care nurses' workload, perceived quality and safety of care, and quality of working life," Health Services Research, vol. 44, no. 2, pp. 422-443, 2009.

[9] J. Johanim, "The structural relationships between organizational structure, job characteristics, work involvement, and job performance among public servants, in College of Business," Universiti Utara Malaysia: Universiti Utara Malaysia, pp. 350, 2010.

[10] A. E.Sarker, "New public management in developing countries: an analysis of success and failure with particular reference to Singapore and Bangladesh," International Journal of Public Sector Management, vol. 19, no. 2, pp. 180-203, 2006.

[11] R. K. Givan, "Seeing stars: human resources performance indicators in the National Health Service," Personnel Review, vol. 34, no. 6, pp. 634-647, 2005.

[12] A. Hondeghem and F. Vandermeulen, "Competency management in the Flemish and Dutch civil service," International Journal of Public Sector Management, vol. 13, no. 4, pp. 342-353, 2000.

[13] S. Horton, "Competency management in the British civil service," International Journal of Public Sector Management, vol. 13, no. 4, pp. 354-368, 2000.

[14] S. Horton, "New public management: its impact on public servant's identity: An introduction to this symposium," International Journal of Public Sector Management, vol. 19, no. 6, pp. 533-542, 2006.

[15] B. P. George and P. G. Hegde, "Employee attitude towards customers and customer care challenges in banks," International journal of bank marketing, vol. 22, no. 6, pp. 390-406, 2004.

[16] M. Wisniewski and S. Ólafsson, "Developing balanced scorecards in local authorities: a comparison of experience," International Journal of Productivity and Performance Management, vol. 53, no. 7, pp. 602-610, 2004

[17] M. Parys, "Staff participation in the Belgian public sector reform," International Journal of Public Sector Management, vol. 16, no. 6, pp. 446-458, 2003

[18] J. I. Mwita, "Performance management model: a systems-based approach to public service quality," International Journal of Public Sector Management, vol. 13, no. 1, pp. 19-37, 2000.
[19] S. K. Pandey and H. G. Rainey, "Public managers' perceptions of organizational goal ambiguity: Analyzing alternative models," International Public Management Journal, vol. 9, no. 2, pp. 85-112, 2006.

[20] J. K. Ito and C. M. Brotheridge, "Exploring the predictors and consequences of job insecurity's components," Journal of Managerial Psychology, vol. 22, no. 1, pp. 40-64, 2007.

[21] D. Wat and M. A. Shaffer, "Equity and relationship quality influences on organizational citizenship behaviors: The mediating role of trust in the supervisor and empowerment," Personnel Review, vol. 34, no. 4, pp. 406-422, 2005.

[22] E. V. Gadot, H. V. Peretz, and E. B. Zion, "Politics and image in the organizational landscape: An empirical examination among public sector employees," Journal of Managerial Psychology, vol. 18, no. 8, pp. 764-787, 2003.

[23] P. M. Schwirian, "Toward an explanatory model of nursing performance," Nursing Research, vol. 30, no. 4, pp. 247-253, 1981.

[24] M. C. Phaneuf and M. A. Wandelt, "Quality Assurance in Nusing:"-any profession that does not monitor itself becomes a technology," in Nursing Forum, Wiley Online Library, 1974.

[25] J. H. Greenslade and N. L. Jimmieson, "Distinguishing between task and contextual performance for nurses: development of a job performance scale," Journal of Advanced Nursing, vol. 58, no. 6, pp. 602-611, 2007.

[26] S. Kim and H. Lee, "The impact of organizational context and information technology on employee knowledge-sharing capabilities," Public Administration Review, vol. 66, no. 3, pp. 370-385, 2006.

[27] P. Garg and R. Rastogi, "New model of job design: motivating employees' performance," The Journal of Management Development, vol. 25 , no. 6 , pp. $572-587,2006$.

[28] J. Johari, K. K. Yahya, and A. Omar, "The mediating role of work involvement in a job characteristics and job performance relationship," presented at 9th Industrial and Organisational Psychology Conference, Brisbane, Australia, 22-26 June 2011.

[29] J. L. J. Lum et al., "Nursing care of oncology patients receiving chemotherapy," Nursing Research November/December, vol. 27, no. 6, pp. 340-345, 1978.

[30] J. G. Baggs, "Issues and rules for authors concerning authorship versus acknowledgements, dual publication, self plagiarism, and salami publishing," Research in Nursing and Health, vol. 31, no. 4, pp. 295-297, 2008

[31] A. Rafferty, J. Ball, and L. Aiken, "Are teamwork and professional autonomy compatible, and do they result in improved hospital care?" Quality in Health Care, vol. 10, suppl 2, pp. 32-37, 2001.

[32] A. Pearson et al., "A comprehensive systematic review of evidence on the structure, process, characteristics and composition of a nursing team that fosters a healthy work environment," International Journal of Evidence Based Healthcare, vol. 4, pp. 118-159, 2006.

[33] M. S. Christian, A. S. Garza, and J. E. Slaughter, "Work engagement: A quantitative review and test of its relations with task and contextual performance," Personnel Psychology, vol. 64, no. 1, pp. 89-136, 2011.

[34] S. P. Lee, C. Bunpitcha, and C. Ratanawadee, "Factors predicting organizational commitment among nurses in state hospitals, Malaysia," International Medical Journal Malaysia, vol. 10, no. 2, pp. 21-28, 2011.

[35] H. K. S. Laschinger et al., "Antecedents and consequences of nurse managers' perceptions of organizational support," Nursing Economics, vol. 24, no. 1, pp. 20, 2006.

[36] J. H. Greenslade and N. L. Jimmieson, "Distinguishing between task and contextual performance for nurses: development of a job performance scale," JAN: Research Methodology, 2007.

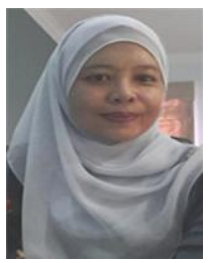

Rohana Mat Som is a senior lecturer/PhD candidate at Universiti Teknologi Mara, Shah Alam. She has obtained her MSc. in education (vocational \& technical education), Virginia Polytechnic and State University (USA) and BA in business education, The University of Toledo (USA). Her area of interest includes healthcare management, human resource management and vocational and technical education

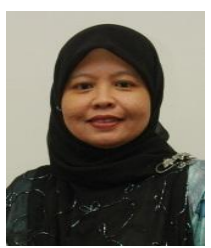

Raja Munirah Raja Mustapha is an associate professor at Faculty of Business Management, Universiti Teknologi Mara, Malaysia. She holds a $\mathrm{PhD}$ from Universiti Putra Malaysia, MBA from Central Michigan, USA and a bachelor degree from Central Michigan, USA. Her research interest includes administrative management and business education. 


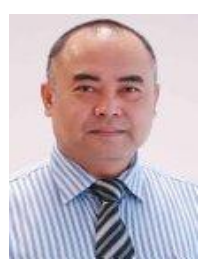

Abdul Kadir Othman is the head of Post-Graduate Studies Faculty of Business Management, Universiti Teknologi Mara, Malaysia. He holds a $\mathrm{PhD}$ from Universiti Teknologi Mara, Malaysia. His research interest includes administrative management and emotional intelligence.

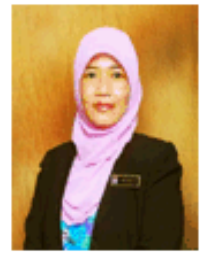

Rozilah Abdul Aziz was born in Kuala Lumpur Malaysia. She is a postgraduate s tudent at Universiti Teknologi Mara, Shah Alam and currently conducting a doctoral research in the field of organizational communication.

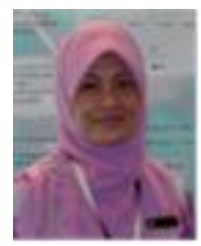

Shereen Noranee is a senior lecturer/Ph.D. candidate, of Universiti Teknologi Mara Malaysia, Puncak Alam, Selangor, Malaysia. She holds a MSc. in human resource development from the Universiti Putra Malaysia, Malaysia and BSc. in business education from University of Nebraska-Lincoln, USA. Her research interest includes human resource management, organizational psychology and organizational behavior. 